\title{
Zielgerichtete Therapie beim nicht-kleinzelligen Lungenkarzinom
}

Im Beitrag „Zielgerichtete Therapie beim nicht-kleinzelligen Lungenkarzinom“ (Dtsch Med Wochenschr 2015; 140: 323328) wurde $>$ Abb. 1 und die zugehörige
Legende nicht korrekt dargestellt. Richtig ist die folgende Abbildung:
Desweiteren ist in Tabelle 1 der korrekte pWert bei LUX-Lung 3/OS (Monate): 0,0374. Außerdem muss es in der letzten Spalte(OS) in der zweiten Zeile richtig heißen: 21,6.

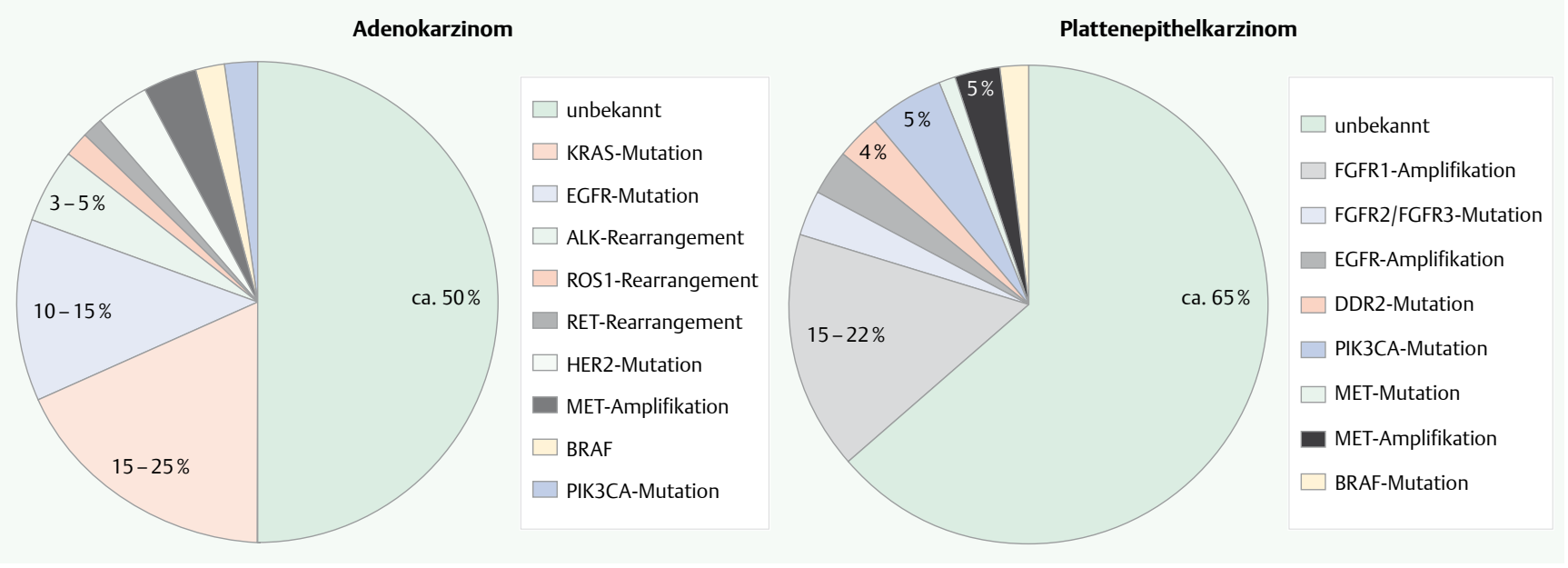

Abb. 1 Molekulare Subtypen des Lungenkarzinoms [11-13]. EGFR und ALK sind beim Adenokarzinom therapierbar durch zugelassene zielgerichtete Substanzen. Andere molekulare Subtypen sind potenziell therapierbar durch Substanzen, die sich beim NSCLC in unterschiedlichen Phasen der klinischen Prüfung befinden. 